\title{
An Investigation of the Impact of Installation of Cd-Lined Irradiation Channel in NIRR-1 on Core Physics Data for ENAA
}

\author{
Sunday Adesunloye Jonah ${ }^{1}$, Raymond Limen Njinga ${ }^{2}$, Yakubu Viva Ibrahim ${ }^{1}$ \\ ${ }^{1}$ Centre for Energy Research and Training, Ahmadu Bello University, Zaria, Nigeria \\ ${ }^{2}$ Physics Department, Ibrahim Badamasi Babangida University, Lapai, Nigeria \\ Email: jonahsa2001@yahoo.com
}

Received November 15, 2013; revised December 21, 2013; accepted January 6, 2014

Copyright (C) 2014 Sunday Adesunloye Jonah et al. This is an open access article distributed under the Creative Commons Attribution License, which permits unrestricted use, distribution, and reproduction in any medium, provided the original work is properly cited. In accordance of the Creative Commons Attribution License all Copyrights (C) 2014 are reserved for SCIRP and the owner of the intellectual property Sunday Adesunloye Jonah et al. All Copyright (C) 2014 are guarded by law and by SCIRP as a guardian.

\section{ABSTRACT}

Prior to the installation of the Cd-liner in one of the large outer irradiation channels of NIRR-1, a Monte Carlo simulation was performed using MCNP5 version 1.4 code. This was done to investigate the effect of installation of Cd-liner in either an inner or outer irradiation channel on reactor physics parameters. Data obtained indicate that the core excess reactivity in both inner and outer irradiations channels is reduced by $3.60 \pm 0.07 \mathrm{mk}$ and $0.64 \pm 0.06 \mathrm{mk}$, respectively. Considering the fact that NIRR-1 has a cold core excess reactivity of $3.77 \mathrm{mk}$, results obtained show that installation of the $1 \mathrm{~mm}$ thick Cd-sheet in one of the large outer irradiation channels would have no significant impact on the core physics data. After installation of a $1 \mathrm{~mm}$ Cd sheath in a large outer irradiation channel, the neutron flux distribution and the stability in the irradiation channels were monitored by foil activation method. Results indicate that the uniformity of neutron flux distribution in the irradiation channel is preserved and the neutron flux data were found to be comparable with the data obtained before the installation.

\section{KEYWORDS}

Monte Carlo Simulation; Core Physics Data; Cd-Liner; NIRR-1

\section{Introduction}

Miniature Neutron Source Reactor (MNSR) facilities are low-power compact nuclear research reactors installed on university campuses for education and training. They are very suitable for Neutron Activation Analysis (NAA) and limited radioisotope production. The commercial MNSR facilities are sited outside China, in Pakistan, Syria, Ghana, Iran and Nigeria.

The Nigeria Research Reactor-1 (NIRR-1) at the Centre for Energy Research and Training, Ahmadu Bello University, Zaria is one of the commercial MNSRs and was commissioned in 2004. Like most commercial miniature neutron source reactors (MNSR) outside China, movable thermal neutron shields in the form of Cd-box or BN capsules are used to perform epithermal neutron activation analysis (ENAA). In order to reduce radiation exposure due to the use of burnable capsules and to extend the scope of analysis suited for elements like I and $\mathrm{Br}$ in biological matrix and also for $\mathrm{U}$, Th, and REEs in geological samples, the MCNP code was used to design a $1 \mathrm{~mm}$ thick Cd-liner in inner and outer channels respectively. This effect is to filter out the thermal $(\mathrm{E}<0.0253$ $\mathrm{eV}$ ) neutron spectrum component, while leaving the epithermal (1 eV $<\mathrm{E}<100 \mathrm{keV}$ ) neutron part relatively unperturbed. ENAA protocol is a well-known technique which improves the sensitivity for the detection of nuclides with high resonance integrals in the presence of elements having high thermal neutron capture cross section especially Na [1-3]. The Monte Carlo codes have been used extensively to simulate the core configuration of NIRR-1 and performed a number of investigations [4-8]. 


\section{Materials and Method}

The NIRR-1 is a compact low-power research reactor which has been designed to be economic, inherently safe and easy to operate. The core is made up of 347 fuel pins with an enrichment of over $90 \%$ and three dummy rods. However, detailed description of the reactor can be found elsewhere [4]. In this work, the MCNP model of NIRR-1 was designed with a $1 \mathrm{~mm}$ thick Cd-lined shield modeled in an inner and an outer irradiation channels to investigate the effect of the installation on core excess reactivity. An MCNP geometrical representation of NIRR-1 axial plane showing $1 \mathrm{~mm}$ thick Cd-liner in the outer irradiation channel is shown in Figure 1. The input files were executed as KCODE source problem for criticality calculations using the MCNP5 code version 1.40, which runs on a Linux Cluster in the computational reactor physics laboratory at the Centre for Energy Research and Training, Ahmadu Bello University, Zaria. It was executed on multiple processors using MPI parallel computing capabilities with MCNP5 executables. All jobs were executed with the "TASK n" option made with 400,000 particles in 400 cycles. One of the basic tally card f $4: \mathrm{N}$, the track length estimate in the cell with different energy bins was constructed for the calculation of axial neutron flux distributions in the irradiation channels according to the 640 group energy structure. The characteristic of the neutron spectral distribution in 640 group energy structure from the MCNP simulation with and without the Cd-liner is shown in Figure 2.

The Cd-shielded irradiation channel, which has now been installed was designed and manufactured by China Institute of Atomic Energy (CIAE), Beijing China. It consists of an inner cylindrical Al tube of $31 \mathrm{~mm}$ in diameter shielded by $1 \mathrm{~mm}$ thick Cd sheath and a height of $25 \mathrm{~cm}$. All of which is embedded in a $39 \mathrm{~mm}$ thick $\mathrm{Al}$ tube with an air passage in between. A cross sectional view of the irradiation tube is depicted in Figure 3.

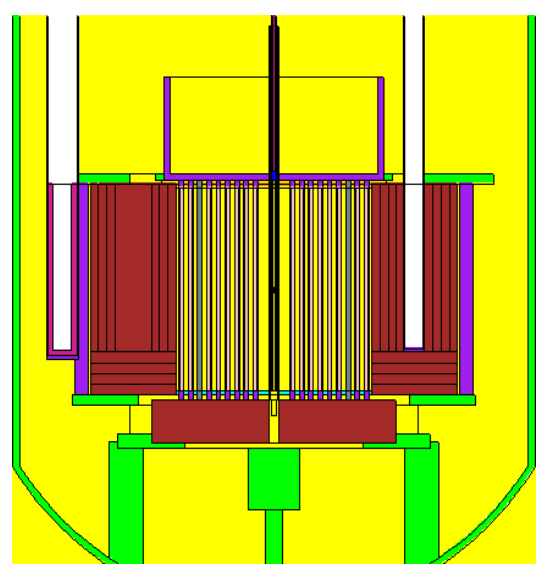

Figure 1. MCNP geometrical representation of NIRR-1 axial plane showing $1 \mathrm{~mm}$ thick Cd-liner in an outer channel.

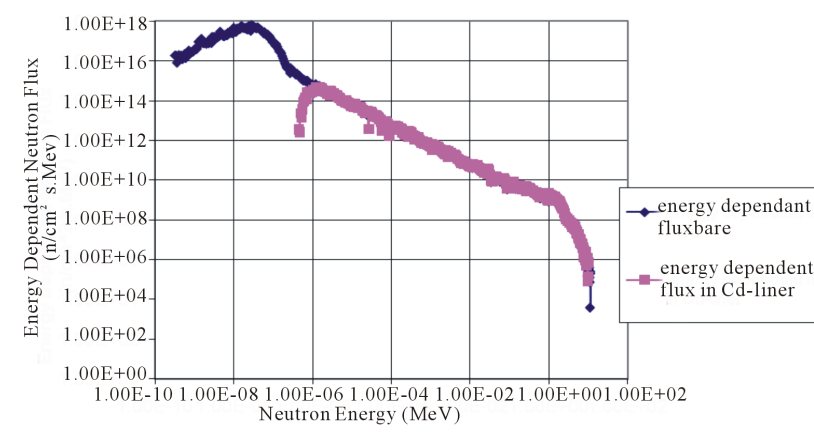

Figure 2. A comparison of MCNP simulated energy-dependent neutron flux in an outer irradiation channel with and without the Cd-liner.

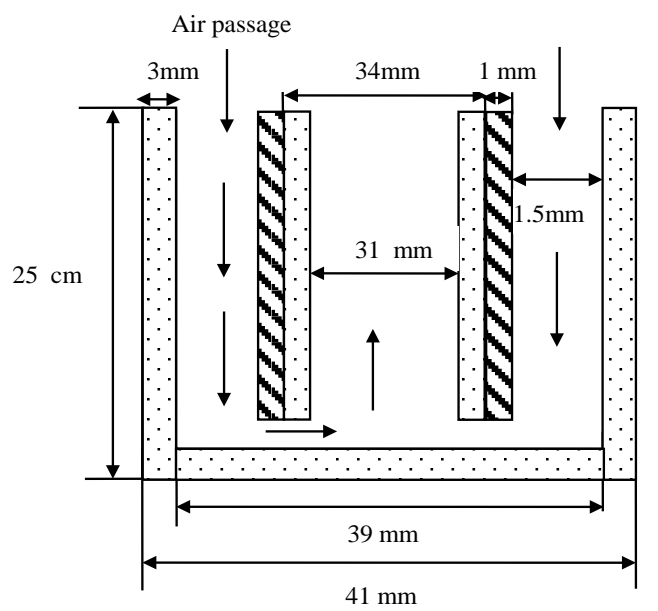

Cd liner $\quad \because \because \because \because$ Al irradiation tube

Figure 3. Schematic diagram of Cd-Liner in outer irradiation channel of NIRR-1.

After installation of the Cd-shielded irradiation channel, the relative neutron flux distributions and stability in the five irradiation channels namely, A1, B2, and B3 (inner irradiation channels) as well as A2 and B4 (outer irradiation channels with A2 as Cd-lined channel) were monitored. The layout of NIRR core configuration showing the irradiation channels is presented in Figure 4. The monitoring was performed using pure copper wires and $\mathrm{Al}-\mathrm{Au}$ (0.1\%), IRMM-530 monitor foil via the nuclear reactions; ${ }^{63} \mathrm{Cu}(\mathrm{n}, \gamma){ }^{64} \mathrm{Cu},{ }^{197} \mathrm{Au}(\mathrm{n}, \gamma){ }^{198} \mathrm{Au}$ and ${ }^{27} \mathrm{Al}(\mathrm{n}$, $\mathrm{p})^{27} \mathrm{Mg}$ respectively. To determine the stability of neutron flux distributions in the irradiation channels, $\mathrm{Cu}$ wire was cut into several pieces made up of weights ranging between 0.0987 and $0.1388 \mathrm{~g}$. They were each packed inside appropriate vials and irradiated in turn for 5 minutes in the respective irradiation channels. Similarly, the thermal, epithermal and fast neutron flux distributions in channels A2 and B2 were determined by irradiating circular pieces of $\mathrm{Al}-\mathrm{Au}$ (0.1\%), IRMM-530 monitor foil. Irradiations were performed for 30 and 120 minutes in channels B2 and A2 respectively, so as to induce suffi- 


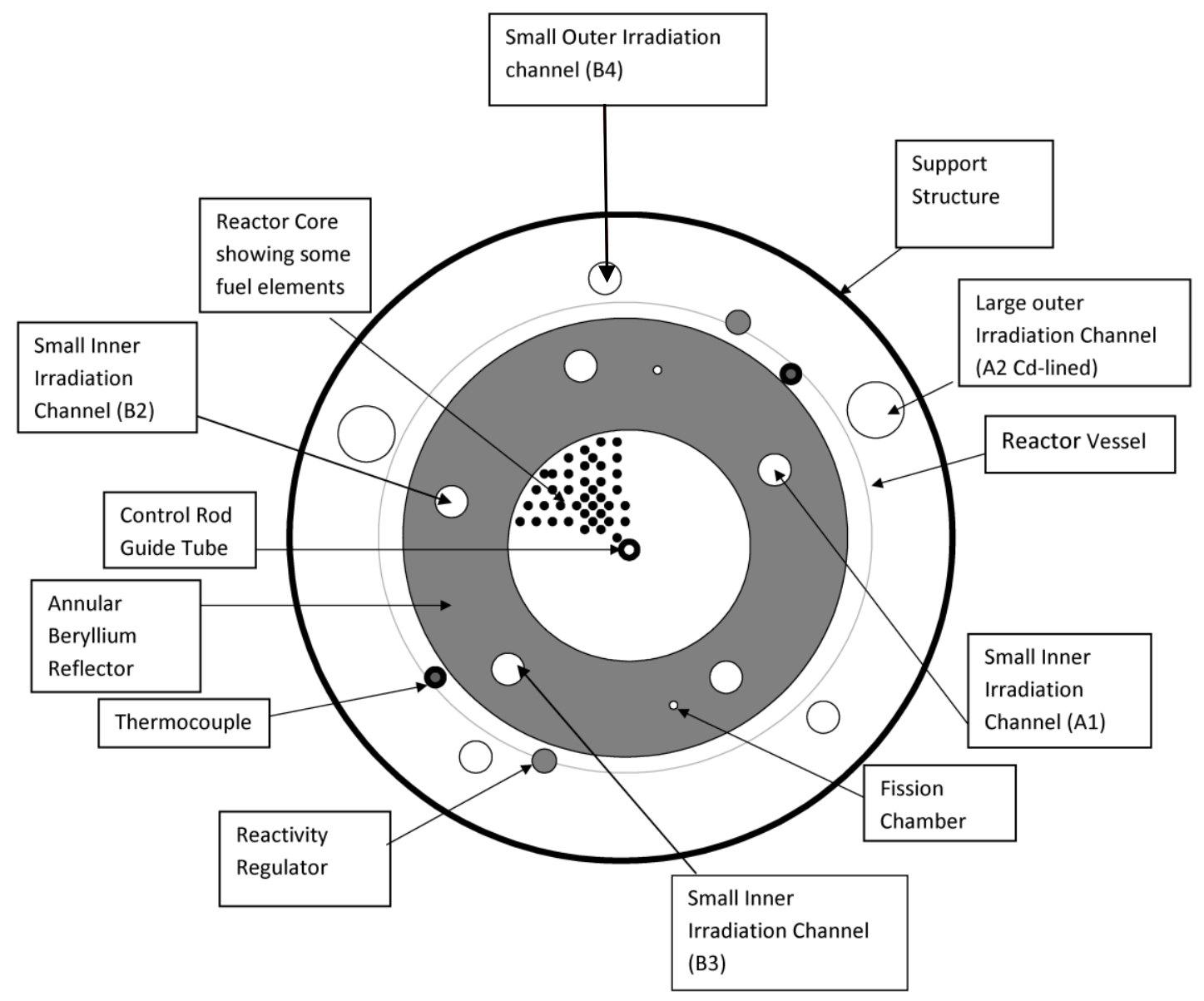

Figure 4. A layout of NIRR-1 core configuration showing the irradiation channels.

cient activities to obtain good counting statistics. All the irradiations were performed at a reactor power of 15.5 $\mathrm{kW}$, which corresponds to a neutron flux of $5.0 \times 10^{11}$ $\mathrm{n} / \mathrm{cm}^{2} \cdot \mathrm{s}$ on the control console. The induced radioactivities based on ${ }^{64} \mathrm{Cu},{ }^{27} \mathrm{Mg}$ and ${ }^{198} \mathrm{Au}$ residual radionuclides were measured on a well calibrated gamma ray spectrometry set up consist of a HPGe detector and electronic modules. Detail description of our gamma ray spectrometry set up has been described elsewhere $[9,10]$. The description of the monitor foils and nuclear data of nuclear reactions used in this work are presented in Table 1.

\section{Results and Discussion}

Two sets of input decks were constructed for the current HEU core of NIRR-1 with and without Cd-liner in an inner and an outer irradiation channels. Results of the $k_{\text {eff }}$ multiplication factors and the core excess reactivity calculated for the two channels are presented in Table 2.

The loss of core excess reactivity $\Delta \rho$ was determined by running the input deck to determine the k-eigen values without Cd liner (i.e. $k_{\text {without }}$ ) and with it in the inner and outer irradiation channels respectively. (i.e. $k_{\mathrm{Cd}}$ ) and fully withdrawn using the relation below.
From the data in Table 2, it can be seen that the loss of core excess reactivity as a result of the installation will reduce the core excess reactivity by $3.60 \mathrm{mk}$ and $0.64 \mathrm{mk}$ in inner and outer Cd-lined sites respectively. As such, the effect of the installation of the Cd-liner in the large outer channel on core excess reactivity is negligible and will preserve the uniformity of the neutron flux in the ten irradiation channels of NIRR-1. Consequently, the CIAE designed large outer irradiation tube with $1 \mathrm{mmm} \mathrm{Cd}$ sheath was found to be suitable for installation in NIRR1 for ENAA.

Furthermore, from the measured activities induced in irradiated $\mathrm{Cu}$ wires, we determined specific activity ratios in the respective channels as depicted in Table 3 . As can be seen, the activity ratios in the inner channels are approximately equal to unity. The activity ratios of innerto-outer indicate that the neutron flux in an inner channel is approximately twice that of an outer channel in line with experimental and theoretical data obtained in previous works before the installation of Cd sheath. A confirmation of this can also be seen in the value of ratio of an inner-to-outer $\mathrm{Cd}$ lined site, approximately equal to 22 , which is twice that of an outer-to-outer $\mathrm{Cd}$ lined site, 
Table 1. Description and nuclear data of activation monitors.

\begin{tabular}{|c|c|c|c|c|}
\hline $\begin{array}{c}\text { Target } \\
\text { nucleus }\end{array}$ & $\begin{array}{l}\text { Product } \\
\text { nuclide }\end{array}$ & $\mathrm{T}_{1 / 2}$ & $\begin{array}{c}E_{\gamma} \\
(\mathrm{keV})\end{array}$ & Description \\
\hline${ }^{197} \mathrm{Au}$ & ${ }^{198} \mathrm{Au}$ & $2.695 \mathrm{~d}$ & 411.8 & $\begin{array}{l}\text { Al-0.1\%Au foil; } \\
0.1 \text { mm thick, } \\
\text { IRMM-530 }\end{array}$ \\
\hline${ }^{27} \mathrm{Al}$ & ${ }^{27} \mathrm{Mg}$ & $9.46 \mathrm{~m}$ & 843.5 & $\begin{array}{l}\text { Al-0.1\%Au foil; } \\
0.1 \text { mm thick, } \\
\text { IRMM-530 }\end{array}$ \\
\hline${ }^{63} \mathrm{Cu}$ & ${ }^{64} \mathrm{Cu}$ & $12.7 \mathrm{~h}$ & & Pieces of Cu wire \\
\hline
\end{tabular}

Table 2. Data of MCNP runs used in the calculation of reactivity effect of installation of Cd-liner in inner and outer channels.

\begin{tabular}{ccc}
\hline Cases & $k_{\text {eff }}$ & Reactivity loss (mk) \\
\hline No Cd-liner & $1.00585 \pm 0.00007$ & - \\
Cd-liner (inner) & $1.00222 \pm 0.00006$ & $3.60 \pm 0.07$ \\
Cd-liner (outer) & $1.00520 \pm 0.00007$ & $0.64 \pm 0.6$ \\
\hline
\end{tabular}

Table 3. Specific activity ratios in irradiation channels of NIRR-1 using Cu wires.

\begin{tabular}{cc}
\hline Channel ratio description & Specific activity ratio \\
\hline Inner-to-inner (A1/B2) & $1.04 \pm 0.04$ \\
Inner-to-inner (B3/B2) & $0.98 \pm 0.04$ \\
Inner-to-inner (A1/B3) & $1.06 \pm 0.05$ \\
Inner-to-outer (A1/B4) & $2.09 \pm 0.08$ \\
Inner-to-outer (B2/B4) & $1.97 \pm 0.09$ \\
Inner-to-outer (B3/B4) & $2.03 \pm 0.08$ \\
Inner-to-outer Cd-lined (A1/A2) & $22.98 \pm 1.18$ \\
Inner-to-outer Cd lined (B2/A2) & $22.10 \pm 1.19$ \\
Inner-to-outer Cd lined (B3/A2) & $22.89 \pm 1.22$ \\
Outer-to-outer Cd lined (B4/A2) & $11.17 \pm 1.13$ \\
\hline
\end{tabular}

approximately equal to 11 . From these data, it can be seen that the neutron flux distribution and stability have not been affected by the installation of $\mathrm{Cd}$ in one of the large outer irradiation channels of NIRR-1.Similarly, using the measured induced activities via ${ }^{198} \mathrm{Au}$ and ${ }^{27} \mathrm{Mg}$ radionuclides, the thermal, epithermal and fast neutron flux values in an inner channel, B2 and the Cd-lined channel, A2 were determined and presented in Table 4. From the results, absolute thermal, epithermal and fast neutron flux data in an inner irradiation channel B2 are comparable with our previous results $[9,10]$. In the Cdlined outer irradiation channel, the absolute value of the fast neutron flux is slightly three times greater than the epithermal flux.

\section{Conclusion}

Investigations were performed by using the MCNP code
Table 4. measured thermal. Epithermal and fast neutron flux using 01\% Au-Al, IRMM-530 foil detector.

\begin{tabular}{lccc}
\hline Channel & \multicolumn{3}{c}{ Measured neutron flux $\mathrm{n} / \mathrm{cm}^{2} \cdot \mathrm{s}$} \\
\hline & Thermal & Epithermal & Fast \\
& & $(2.55 \pm$ & $(9.82 \pm$ \\
Ch. B2 & $(4.89 \pm$ & $0.66) \mathrm{E}+10$ & $0.79) \mathrm{E}+10$ \\
Ch. A2 & $0.25) \mathrm{E}+11$ & $(4.82 \pm$ & $(1.65 \pm$ \\
& - & $0.21) \mathrm{E}+09$ & $0.68) \mathrm{E}+10$ \\
\hline
\end{tabular}

to check the effects of installation of a permanent epithermal neutron irradiation channel in either the inner or the outer site of NIRR-1. Using a Cd-shield of $1 \mathrm{~mm}$ thickness, the reactor core excess reactivity was calculated for installation in an inner and an outer site, respectively. Data obtained indicate that installation in an inner channel will reduce the cold core excess reactivity significantly, thereby following the installation of $1 \mathrm{~mm}$ thick Cd sheath in a large outer irradiation channel, necessitating the addition of shims to achieve the recommended licence range of 3.5 - $4.0 \mathrm{mk}$. However, the reduction in reactor cold core excess reactivity is negligible if the Cd shield is installed in an outer. Consequently, a Cd-lined irradiation tube was designed and has since been installed in NIRR-1 for ENAA. Results of measurements performed by using activation detector foils/ wires indicate that the neutron flux distribution and stability were preserved.

\section{Acknowledgement}

This work was supported by the IAEA under the CRP entitled "Conversion of Miniature Neutron Source Reactor to LEU” No. NIR/13934 and UCHICAGO ARGONNE, LLC Operator of ANL Contract No. IF30204, Lemont, Illinois, USA.

\section{REFERENCES}

[1] C.-Y. Chen, Y.-Y. Wei S.-P. ChangLai and L.-K. Pan, "Bromine and Iodine in Chinese Medical Herbs Determinedvia Epithermal Neutron Activation Analysis” Journal of Radioanalytical and Nuclear Chemistry, Vol. 257, No. 2, 2003, pp. 405-410. http://dx.doi.org/10.1023/A:1024708518645

[2] S. Parry, "Activation Spectrometry in Chemical Analysis,” John Wiley \& Sons, Inc., Hoboken, 1991.

[3] X. Hou, K. Wang and C. Chai, "Epithermal Neutron Activation Analysis and Its Applications in the Miniature Neutron Source Reactor,” Journal of Radioanalytical and Nuclear Chemistry, Vol. 210, No. 1, 1997, pp. 137-148. http://dx.doi.org/10.1007/BF02055413

[4] S. A. Jonah, J. R. Liaw and J. E. Matos, "Monte Carlo Simulation of Core Physicsparameters of the Nigeria Research Reactor-1(NIRR-1)," Annals of Nuclear Energy, Vol. 34, No. 12, 2007, pp. 953-957. 
http://dx.doi.org/10.1016/j.anucene.2007.05.010

[5] S. A. Jonah, K. Ibikunle and Y. Li, “A Feasibility Study of LEU Enrichment Uraniumfuels for MNSR Conversion Using MCNP,” Annals of Nuclear Energy, Vol. 36, No. 8, 2009, pp. 1285-1286. http://dx.doi.org/10.1016/j.anucene.2009.05.001

[6] S. A. Jonah, Y. V. Ibrahim, A. S. Ajuji and M. Y. Onimisi, "The Impact of HEU to LEU Conversion of Commercial MNSR: Determination of Neutron Spectrum Parameters in Irradiation Channels of NIRR-1 Using MCNP code,” Annals of Nuclear Energy, Vol. 39, No. 1, 2012, pp. 15-17. http://dx.doi.org/10.1016/j.anucene.2011.08.026

[7] Y. V. Ibrahim, H. C. Odoi, R. L. Njinga, M. O. Adeleye and S. A. Jonah, "Monte Carlo Simulation of Additional Safety Control Rod for Commercial MSNR to Enhance Safety," Annals of Nuclear Energy, Vol. 44, 2012, pp. 7175. http://dx.doi.org/10.1016/j.anucene.2012.01.008
[8] Y. V. Ibrahim, H. C. Odoi, J. W. Thomas and S. A. Jonah, "Design Options of Control Rod for Low Enriched Uranium Fueled NIRR-1 Using Monte Carlo N-Particle Code," International Journal of Nuclear Energy Science and Technology, 2013. http://dx.doi.org/10.4172/2325-9809.1000104

[9] S. A. Jonah, G. I. Balogun, I. M. Umar and M. C. Mayaki, "Neutron Spectrum Parameters in Irradiation Channels of the Nigeria Research Reactor-1 (NIRR-1) for the $k 0$-NAA Standardization” Journal of Radioanalytical and Nuclear Chemistry, Vol. 266, No. 1, 2005, pp. 83-88. http://dx.doi.org/10.1007/s10967-005-0873-8

[10] S. A. Jonah, U. Sadiq, I. O. Okunade and I. I. Funtua, "The Use of the k0-IAEA Program in NIRR-1 Laboratory" Journal of Radioanalytical and Nuclear Chemistry, Vol. 279, No. 3, 2009, pp. 749-755. http://dx.doi.org/10.1007/s10967-008-7347-8 